\title{
As identidades docentes como fabricação da docência
}

\author{
Maria Manuela Alves Garcia \\ Álvaro Moreira Hypolito \\ Jarbas Santos Vieira \\ Universidade Federal de Pelotas
}

\section{Resumo}

Neste trabalho se discute como os docentes têm sido vistos e posicionados especialmente pelos discursos educacionais das últimas décadas, analisando-se como têm sido definidas a sua situação ocupacional e a profissionalização do ponto de vista dos estudos do campo educacional. Discute-se a identidade em relação às posições de sujeito, que são atribuídas aos professores e às professoras no exercício de suas funções em contextos laborais concretos, e, ainda, em relação ao conjunto das representações postas em circulação pelos discursos relativos aos modos de ser e agir dos professores e professoras no exercício de suas funções. Exploram-se os argumentos quanto aos modelos de profissionalismo que transitam como mais ou menos adequados e debatem-se possíveis implicações desses modelos na construção das identidades docentes. Busca-se, também, mostrar como as reestruturações educativas das últimas décadas, ao estimular certos modelos de profissionalismo, constroem identidades docentes mais ou menos articuladas aos objetivos últimos das reformas, e assim procurar revelar contradições, avanços, limites e possibilidades em cada um deles. Por fim, discutem-se alguns aspectos teórico-metodológicos para investigações sobre a identidade docente, indicando que um dos caminhos produtivos para a pesquisa nesse campo pode ser a busca das diferenças, das descontinuidades, das divisões dessa categoria, privilegiando as narrativas dos professores e das professoras acerca de si mesmos e de seus contextos de trabalho.

\section{Palavras-chave}

Identidade - Trabalho docente - Profissionalismo - Formação de professores.

Correspondência:

Álvaro Moreira Hypolito

Faculdade de Educação - UFPel

Rua Alberto Rosa, 154

96010-770 - Pelotas - RS

E-mail: hypolito@ufpel.tche.br 


\title{
Teacher identities as a production of teaching
}

Maria Manuela Alves Garcia

Álvaro Moreira Hypolito

Jarbas Santos Vieira

Universidade Federal de Pelotas

\begin{abstract}
The work discusses how teachers have been seen and situated, in particular by the educational discourses of the last decades, analyzing how their occupational and professional situations have been defined from the viewpoint of the studies in the educational field. The issue of identity is discussed in its relation with the position of subject that is attributed to teachers in performing their roles within concrete labor contexts, and also in its relation to the set of representations circulated by the discourses about the manners of being and acting of teachers in the exercise of their functions. The text explores the arguments around models of professionalism that circulate as more or less adequate, and it debates possible implications of such models to the construction of teacher identities. It also seeks to show how the educational restructuring of the last decades, by stimulating certain models of professionalism, bring forth teacher identities more or less articulated with the ultimate goals of the reforms, and in doing so the text tries to reveal contradictions, steps forward, limits and possibilities in each one of the models. Lastly, the article discusses some theoretical-methodological aspects in the study of teacher identities, indicating that one of the productive paths for the research in this field can be the search for differences, for discontinuities, for divisions in this professional category, emphasizing teachers' discourses about themselves and about their work contexts.
\end{abstract}

\section{Keywords}

Identity - Teaching - Professionalism - Teacher education.

Contact:

Álvaro Moreira Hypolito

Faculdade de Educação - UFPel

Rua Alberto Rosa, 154

96010-770 - Pelotas - RS

e-mail: hypolito@ufpel.tche.br 
Quando se fala de uma identidade da categoria docente, dos traços e dos aspectos que caracterizam esse grupo tão heterogêneo, poderíamos pensar imediatamente neste: todos se dedicam ao ensino. Essa é uma característica comum. Mas mesmo considerando esse aspecto aparentemente geral, quando pensado em seus efetivos processos de significação, dele só emergem diferenças.

Os docentes são uma categoria amplamente constituída por mulheres, pelo menos no ensino básico. Exercem seu trabalho em instituições e sistemas de ensino diferenciados por nível e jurisdição: são professoras da educação infantil, professoras do ensino fundamental, do ensino médio, do ensino superior, de estabelecimentos públicos, privados, confessionais, oficiais, formais, não-formais. A marca é a heterogeneidade. E isso traz questões de vulto e urgentes tanto para o estudo dessa ocupação como para o encaminhamento de nossas lutas políticas e sindicais. As condições de trabalho e os interesses desses sujeitos, conforme sua posição profissional e institucional, são profundamente diferentes. Também a formação e qualificação em termos profissionais, conforme o lugar em que a docente atua e o que ensina, são profundamente distintas (a educadora de crianças com menos de 6 anos, a professora primária, a pedagoga ou a licenciada em uma área de conhecimento específica têm a formação profissional bastante diversas em termos dos conhecimentos e habilidades específicas necessários à docência).

Por outro lado, professoras são a todo o momento seduzidas e interpeladas por discursos que dizem como elas devem ser e agir para que sejam mais verdadeiras e perfeitas em seu ofício. Diferentes "regimes do eu" e formas de subjetivação concorrem para essas definições e lutam pela imposição de significados acerca de quem as professoras devem ser em determinadas conjunturas, como devem agir e qual o projeto formativo que docentes e escolas devem levar adiante perante os desafios da cultura e do mundo contemporâneo.
Tratar da identidade docente é estar atento para a política de representação que instituem os discursos veiculados por grupos e indivíduos que disputam o espaço acadêmico ou que estão na gestão do Estado. É considerar também os efeitos práticos e as políticas de verdade que discursos veiculados pela mídia impressa, televisiva e cinematográfica estão ajudando a configurar. A identidade docente é negociada entre essas múltiplas representações, entre as quais, e de modo relevante, as políticas de identidade estabelecidas pelo discurso educacional oficial. Esse discurso fala da gestão dos docentes e da organização dos sistemas escolares, dos objetivos e das metas do trabalho de ensino e dos docentes; fala também dos modos pelos quais são vistos ou falados, dos discursos que os vêem e através dos quais eles se vêem, produzindo uma ética e uma determinada relação com eles mesmos, que constituem, a experiência que podem ter de si próprios.

Como diz Martin Lawn (2001), a gestão da identidade profissional dos docentes é uma tarefa central no governo e na condução do sistema educacional e escolar de uma nação. Definir pelo discurso que categoria é essa, como deve agir, quais suas dificuldades e problemas é produzir uma parcela das condições necessárias à fabricação e à regulação da conduta desse tipo de sujeito.

São diversos os veículos desse discurso e alto o poder de penetração das demandas oficiais em jornais, nos comentários educacionais veiculados pela mídia, nos periódicos especializados, etc. Enunciados sobre a escola e os docentes são recorrentes e povoam o universo simbólico acerca da educação, das instituições escolares e dos seus agentes, autorizando expectativas e produzindo uma demanda por determinado tipo de identidade. Na última década, segundo os discursos educacionais, os professores têm sido apontados como os grandes responsáveis pelo fracasso do sistema escolar público e pelo insucesso dos alunos. Esse discurso interpelou e vem interpelando os docentes da escola pública dos ensinos fundamental 
e médio (Anadon; Garcia, 2004; Hypolito et al., 2003), produzindo uma demanda que vem justificando as políticas de formação e certificação profissional propostas nos últimos anos.

Por outro lado, as identidades docentes não se reduzem ao que os discursos oficiais dizem que elas são. Eles são mais que meros formadores de cidadãos, como querem as políticas curriculares oficiais. Negociam suas identidades em meio a um conjunto de variáveis como a história familiar e pessoal, as condições de trabalho e ocupacionais, os discursos que de algum modo falam do que são e de suas funções.

Como os docentes têm sido vistos e posicionados especialmente pelos discursos educacionais das últimas décadas? Como têm sido definidas a situação ocupacional e a profissionalização dos docentes do ponto de vista dos estudos do campo educacional? Que modelos de profissionalismo nos são apresentados como mais ou menos adequados? Que modos de organização do trabalho pedagógico nos são sugeridos como mais desejáveis? Modelo do trabalho flexível? Modelo colaborativo? Modelo centrado na prática? Que deslocamentos de nossa identidade é saudável incitar nos dias de hoje?

\section{Identidade: um constructo em ação na análise da docência}

Por identidade profissional docente entendem-se as posições de sujeito que são atribuídas, por diferentes discursos e agentes sociais, aos professores e às professoras no exercício de suas funções em contextos laborais concretos. Refere-se ainda ao conjunto das representações colocadas em circulação pelos discursos relativos aos modos de ser e agir dos professores e professoras no exercício de suas funções em instituições educacionais, mais ou menos complexas e burocráticas.

Alguns estudos que tratam dessas questões já são clássicos entre nós. Especialmente os que tratam a identidade docente do ponto de vista da análise da situação ocupacional dos docentes, considerando suas posições de acor- do com os processos de trabalho escolar. Temas como a autonomia profissional e o menor ou maior grau de proletarização ou as características de profissionalismo dos docentes têm sido problematizados.

No final da década de 1980, o principal debate sobre a profissão docente era em torno da conceituação de classe social e sobre a natureza do trabalho docente, principalmente com a publicação de alguns artigos que demarcaram e estimularam as discussões (Apple, 1987; 1988; Arroyo, 1985). Debatia-se, então, se os professores e as professoras realizavam um trabalho produtivo ou improdutivo ou, em outras palavras, se a natureza do trabalho que realizavam era capitalista ou não, e se pertenciam, como grupo social, à classe trabalhadora ou à classe média, como tradicionalmente haviam sido considerados até então por estudos sociológicos clássicos.

De uma perspectiva neomarxista, alguns trabalhos empregaram as dinâmicas de gênero e classe social para uma interpretação do trabalho docente no Brasil (Hypolito, 1994; 1997; Vieira, 1992). Hypolito desenvolve uma análise da constituição histórica do professorado no Brasil, na qual discute aspectos da composição social e da natureza de classe do magistério, baseando seus argumentos na idéia de ambivalência de classe que vive esse grupo social, com características ao mesmo tempo de classe trabalhadora e de classe média (Apple, 1988), e na ambigüidade da docência, formulada por Fernandéz Enguita (1991). No estudo de Hypolito há também um esforço de compreender o processo de feminização do magistério, articulando categorias como gênero e classe social, bem como a influência do patriarcado e da vocação como ideologias reinantes na formação da identidade docente como trabalho de mulher (Hypolito, 1994; 1997). Por fim, neste mesmo estudo, são discutidas a natureza do trabalho docente e a teoria da intensificação, considerando-se aspectos econômicos e organizacionais do processo de trabalho, de acordo com uma abordagem que articula clas- 
se, gênero e profissionalização em busca de uma interpretação do professorado como trabalhadores culturais e intelectuais reflexivos (Hypolito, 1994; 1995).

Em pesquisa realizada com professoras da rede pública de ensino, diferentemente daquilo que vinha afirmando a teoria da proletarização, Vieira (1992) encontrou uma série de contradições entre as demandas das políticas educacionais e curriculares oficiais e as práticas e concepções desenvolvidas pelas professoras no seu cotidiano de trabalho. As professoras não se viam totalmente apartadas das funções conceptuais do seu trabalho, garantindo um relativo controle sobre o ensino que desenvolviam, limitando as tentativas do Estado e do capital em conformar o trabalho escolar às suas demandas.

0 conceito de controle, pelo menos nas duas últimas décadas, começou a tornar-se central para a compreensão do trabalho docente e, por conseguinte, para a compreensão da produção e distribuição do conhecimento escolar. Entretanto, o controle deveria ser compreendido para além de todo e qualquer tipo de determinismo sociológico, como uma relação de poder e não como propriedade do Estado, do capital ou de uma classe (Vieira, 2004).

Isso, todavia, não impede que a profissionalização docente, em boa medida, seja atingida pelas políticas neoliberais de reestruturação educativa (Hypolito; Vieira, 2002). Essas não só tendem a conformar o processo de trabalho docente, como também a definir novas identidades docentes. Em estudos nessa linha, analisam-se essas reformas e seus efeitos sobre o trabalho docente de uma perspectiva que articula teoria crítica com elementos do pós-estruturalismo (Ball, 1994), considerando as ressignificações que os docentes fazem das diretrizes educacionais oficiais em seus contextos locais:

Os professores e as professoras possuem interesses e identidades ligadas a gênero, raça e classe social. As contradições existentes nas lutas sociais e políticas de negação ou de afirmação das culturas das mino- rias e de diferentes grupos étnico-raciais, em relação com as classes sociais, envolvem também os/as docentes. Os professores e as professoras, ao verem-se obrigados a padronizar o ensino desde a perspectiva de uma cultura padrão - centrada na masculinidade, na branquidade, no cristianismo e no eurocentrismo -, vêem-se diante de relações políticas de poder que envolvem seus próprios interesses de gênero, de classe social e étnico-raciais. (Hypolito; Vieira, 2002, p. 280)

Assim, pode-se considerar que, para a construção de uma identidade docente,

tanto as formas de controle sobre o trabalho docente pretendidas pelas políticas de padronização quanto as práticas de contestação e resistência desencadeadas por docentes não estão estabelecidas a priori. As possibilidades de legitimação ou de deslegitimação dessas políticas neoliberais por parte das ações docentes, envolvem não só os interesses dos/as estudantes mas os próprios interesses docentes como sujeitos que constroem suas identidades. (Hypolito; Vieira, 2002, p. 280)

A partir das considerações e argumentos até aqui expostos, na próxima seção apresentaremos, de forma breve, argumentos sobre modelos de profissionalismo e suas implicações para a identidade docente.

\section{Modelos de profissionalismo e identidade docente}

0 que está efetivamente em jogo são disputas em torno das diferentes concepções de identidade, profissionalismo e profissionalização. Disputa-se o controle sobre as professoras e professores, sobre seus processos de trabalho e sobre os significados que circulam ou podem circular no âmbito da educação.

Vários estudos têm-se debruçado sobre o 
tema do profissionalismo docente a fim de captar os desenvolvimentos históricos que vêm configurando o trabalho docente e os discursos sobre profissionalismo (Robertson, 2002; Lawn, 2001; Hargreaves; Goodson, 1996). Esta seção expõe um pouco desse debate no que se refere a aspectos da profissionalização docente e das diferentes concepções de profissionalismo, baseando a classificação e os principais argumentos apresentados nos trabalhos de Hargreaves e Goodson (1996).

\section{Profissionalismo clássico}

0 profissionalismo, concebido numa versão clássica, é a marca de todo trabalho que tem como meta atingir o status de outras profissões consideradas altamente qualificadas, tais como as de médicos e advogados. Obter status profissional e reconhecimento, ou seja, obter os padrões dessas posições, significa estar bem colocado numa classificação das profissões, ter prestígio público e, por último, pertencer a uma profissão masculinizada. Ninguém busca espelhar-se naquelas profissões de menor reconhecimento (odontologia, arquitetura, etc.) tampouco nas ditas "semiprofissões" femininas, tais como as de enfermeira, assistente social ou bibliotecária. Nessa visão de profissionalismo há uma tendência de reforçar e celebrar os modelos profissionais com mais status. Tal perspectiva fundamenta-se na existência de um conhecimento especializado, baseado em "certezas científicas”; em uma cultura técnica partilhada por todos; em órgãos reguladores dos aspectos ético-profissionais; e, por fim, na auto-regulação como controle sobre as formas de ingresso na carreira e as políticas de formação, sobre os aspectos da ética e sobre os padrões para o exercício prático da profissão. Todos os estudos que têm confrontado a profissão docente com esses critérios encontram a docência como uma atividade não-profissional ou semiprofissional. $\mathrm{Na}$ perspectiva do profissionalismo clássico, a relação com a comunidade será sempre uma relação formal e de submissão ao conhecimento técnico dos profissionais.

\section{Profissionalismo como trabalho flexivel}

A noção de profissional flexível está centrada na redefinição dos aspectos técnicos do trabalho docente de acordo com uma estratégia de desenvolvimento de culturas de colaboração e de comunidades profissionais solidárias. A construção dessa perspectiva com grupos específicos de docentes em escolas ou disciplinas específicas tem como finalidade o diálogo sobre ensino e melhoria da qualidade do trabalho pedagógico. No entanto, muitas vezes essas práticas de colaboração podem ser colonizadas e controladas pelas burocracias educacionais, tornando tais práticas uma verdadeira "camisade-força" ora pela imposição de formas colegiadas de trabalho, ora por procedimentos burocráticos que são a própria antítese de um profissionalismo autônomo e autogestionário.

Mesmo assim essa perspectiva pode fortalecer de fato as comunidades de trabalho, enriquecer o diálogo entre as comunidades docentes e abrir a possibilidade de soluções criativas, embora restem algumas preocupações tais como: a relação com as comunidades do entorno escolar freqüentemente pode ser esquecida, e o grupo pode continuar fazendo um trabalho isolado e solitário; o mesmo pode-se dizer da relação com outros grupos docentes, tanto aqueles da própria escola quanto de outras comunidades escolares; isso poderia, então, conduzir ao que se pode chamar de comunidades "fragmentadas"; e todo o investimento de um elevado profissionalismo dirigido para um "localismo" poderia significar uma fragmentação docente. A noção de profissionalismo e profissionalização concebidos a partir das comunidades docentes locais substitui os princípios das "certezas científicas" por principios das "certezas situadas" como base para o profissionalismo docente (Hargreaves; Goodson, 1996). É por isso que a noção de profissionalismo como trabalho flexível influencia a identidade docente à medida que pode conduzir as práticas docentes segundo critérios flexíveis dependentes de cada localismo. 


\section{Profissionalismo como trabalho prático}

Ao invés de considerar o profissionalismo como algo fora do alcance e a profissionalização como algo que pode ser acrescentado desde fora, através de uma ciência teórica produzida alhures, a visão da docência como profissional prático entende que essa é uma atividade cujos saberes coincidem com os saberes práticos, experienciais, os quais são moldados por valores e propósitos dos professores e das professoras que constroem suas próprias práticas educativas.

Uma extensão vigorosa desse discurso é a noção de "prática reflexiva", da qual origina-se a concepção de docente como "prático-reflexivo" (intelectual reflexivo). Nessa perspectiva, só é capaz de emitir julgamentos quem basear sua ação a partir de reflexões sobre a própria prática. Essa noção amplia o campo de questionamento ao enfatizar a necessidade de uma visão mais reflexiva e critica sobre as ações (como faz Zeichner, por exemplo). Essa perspectiva contribui muito para o questionamento do conhecimento como saber acadêmico ou como saber "científico", permitindo uma visão critica mais avançada e pode ajudar também a conectar a reflexão prática docente às agendas sociais de emancipação e igualdade, permitindo à reflexão prática uma reflexão social e crítica, bem como pessoal e local. Contudo, quando essa visão fica reduzida a uma perspectiva romântica e individualizada pode conduzir a resultados preocupantes. Nem todas as práticas e reflexões docentes são valiosas e acertadas. Por exemplo, docentes em início de carreira tendem a agir conforme arquétipos de ensino amplamente aceitos na nossa cultura. Freqüentemente, são modelos tradicionais e moldam-se a partir de exemplos caricatos da docência.

Outro argumento a ser considerado é que o discurso do saber docente como reflexão prática, ao superestimar o cotidiano docente e sobrevalorizar o saber experiencial, pode distanciar os professores e as professoras daqueles objetivos sociais e morais mais amplos que acabam sendo definidos exclusivamente pelas políticas educacionais e governamentais.

\section{Profissionalismo como trabalho extensivo}

0 conceito de profissional extensivo parte da diferenciação entre profissionalidade restrita e profissionalidade extensiva. Na profissionalidade restrita, as habilidades docentes derivam da experiência; a perspectiva está no aqui e agora; os acontecimentos da sala de aula são tomados isoladamente; as metodologias são decisões de foro intimo; a autonomia individual é valorizada; há pequeno envolvimento com aquelas atividades profissionais não diretamente relacionadas com o ensino, tais como leituras de formação políticoprofissional mais ampla ou participação em atividades de formação em serviço que não sejam cursos "práticos" orientados a um saber-fazer; o ensino tende a ser visto como intuitivo por natureza - por vocação. Na segunda, profissionalidade extensiva, as habilidades docentes derivam da mediação entre teoria e experiência; a perspectiva dos docentes vai além da sala de aula para alcançar o contexto social mais amplo da educação; a sala de aula é percebida na relação com outros acontecimentos da escola; as metodologias de trabalho resultam da troca de experiência com a comunidade docente; outras atividades são valorizadas, tais como literatura da área ou atividades de formação em serviço, tanto as de interesse mediato como as de interesse imediato; o ensino é visto como atividade racional mais do que intuitiva. Hargreaves e Goodson, todavia, incluem as características de uma profissionalidade extensiva no contexto do que chamam de "novo" profissionalismo resultante das reformas educacionais conservadoras na Inglaterra e País de Gales.

Susan Robertson mostra as conseqüências dessas reformas para o trabalho docente quando afirma que

Há pouco alcance na promessa do profissionalismo para aumentar o grau de autonomia porque a reserva crucial de determinação - que é um controle ideológico - tem sido sem cerimônia retirada das professoras e dos professores e alocada nas mãos firmes dos 
administradores, dos políticos e do capital transnacional. A reserva de indeterminação é então colocada num nível de decisões para que os resultados específicos do sistema sejam atingidos, e não num ponto de julgamento sobre o que poderia constituir um referencial adequado de conhecimento. Benefícios para os/as professores/as são assim em grande medida ilusórios. Docentes serão oprimidos pela pressão do (auto)gerenciamento, restrições de tempo, turmas maiores e gerência de outros trabalhadores/as sobre o seu trabalho. 0 que decorre daí é uma autoridade despersonalizada - uma docência de resultados confundida com profissionalismo. Aos/às docentes não têm sido dada ou prometida a oportunidade para negociar os novos moldes do seu trabalho. Ao contrário, o trabalho docente tem sido crescentemente moldado pelos imperativos e conveniências econômicas, e é o resultado das necessidades do Estado em estabelecer as novas condições para acumulação. (1996, p. 16)

Este "novo" profissionalismo estaria sendo requisitado para a efetiva consecução dos padrões de um currículo nacional como parte da reestruturação econômica do capitalismo, no atual contexto da globalização. As marcas discursivas desse "novo" profissionalismo, além do currículo nacional, são a colaboração, o trabalho integrado, a equipe, a parceria, a tutoria, o desenvolvimento profissional e o foco nos resultados. Entretanto, estudos mostram que, apesar do discurso da profissionalidade extensiva, as orientações de um currículo nacional, tais como os PCNs, colocam os docentes numa "camisa-deforça”, como se estivessem "ensinando numa caixa fechada”. Essas práticas, mais do que reforçar o planejamento global da escola e o poder de decisão, sobrecarregam o trabalho docente com tarefas e responsabilidades extras, intensificando o trabalho de tal forma que resta cada vez menos tempo para preparação das atividades de sala de aula. Muito embora alguns docentes consigam redirecionar suas práticas para formas alternativas e críticas de trabalho, estas não passam, muitas vezes, de formas de resistência restritas a pequenos grupos.

\section{Profissionalismo como trabalho complexo}

As rápidas mudanças provocadas pela globalização e pelas modificações econômicas globais e locais têm afetado o trabalho docente e não são, como muitos poderiam pensar, mudanças cosméticas somente. Mas elas estariam tornando o trabalho docente mais complexo e difícil, mais do que um trabalho extensivo e sobrecarregado? Certos autores pensam que o trabalho docente deve ser encarado como um trabalho de alto grau de complexidade, assim como outras profissões, e que deve ser julgado pela complexidade das tarefas.

Há de se admitir que vários aspectos do trabalho docente podem ter ficado mais complexos, mesmo que muitos dos critérios utilizados para se fazer este julgamento estejam baseados em características do trabalho docente dos anos 1980, as quais teriam sido perdidas na década seguinte. Mesmo tratando-se de uma realidade de países desenvolvidos, é oportuna a seguinte consideração:

Em 1885, os/as docentes eram formados em salas de aula para desempenhar funções específicas de instrução e de controle. No transcorrer do século seguinte, transformaram-se em profissionais altamente educados. Em 1985, mesmo continuando com o ensino e o controle em salas de aula, transformaram-se em um corpo altamente formado em teorias e práticas educacionais, sociologia, teoria social, psicologia infantil, teorias da aprendizagem e assim por diante. Transformaram-se em especialistas nos seus conteúdos disciplinares; conquistaram o direito, como corpo profissional, a estar muito envolvidos na determinação e no desenvolvimento dos conteúdos curriculares, das práticas escolares e da política educacional em geral. Em 1995, os/as docentes provavel- 
mente perderam, numa única década, a maior parte das conquistas realizadas num único século. (Harris apud Robertson, 1996, p. 28 - tradução nossa)

Contudo, mesmo que se admita uma maior complexidade do trabalho docente planejamento coletivo, poder de decisões, uso de computadores, avaliação com portfólio, avaliação colaborativa, etc. -, o que preocupa é que essas atribuições em certas áreas do processo de ensino excluem outras áreas mais políticas e sociais do trabalho a ser realizado. Decisões sobre currículo e objetivos finais da educação, sobre o direcionamento da educação de seus estudantes, têm se tornado menos "complexas" e têm sido retiradas do âmbito de poder e da autonomia docente. Se cabe aos docentes reorganizar o trabalho mais complexo que lhes compete em face das demandas colocadas com as mesmas condições de tempo e de trabalho atuais, isso poderá significar aparente aumento de profissionalismo a curto prazo, porém a longo prazo pode significar mais intensificação em seu trabalho e maior desgaste para a sua saúde (Codo, 1998). Considerando isso, Hargreaves e Goodson concluem que

a menos que governos, administradores e docentes conjuntamente possam tratar e resolver esses deságios da reestruturação do trabalho docente com abertura, compromisso e flexibilidade, é provável que o profissionalismo complexo - o profissionalismo que vem com aumento da complexidade do trabalho - simplesmente tornar-se-á para o trabalho docente um sinônimo de exploração e burnout! (1996, p.1-9 - tradução nossa)

E propõem como alternativa um profissionalismo pós-moderno, também definido como profissionalismo interativo, que teria as seguintes características: aumento das oportunidades e responsabilidades para exercer julgamento discricionário sobre temas do ensino, currículo e cuidados que afetam o alunado; engajamento com os propósitos morais e sociais e com os valores do que ensinar, ao lado dos problemas de currículo e avaliação em que esses propósitos estão incluídos; trabalhar em culturas colaborativas de apoio, a fim de partilhar o conhecimento especializado e resolver os problemas advindos da prática profissional, ao invés de se engajar em trabalhos conjuntos como mecanismo motivacional para implementação de ordens decididas externamente; heteronomia ocupacional no lugar de uma autonomia autoprotetora; compromisso com um cuidado ativo e não somente com um serviço analgésico para estudantes; luta e busca autodirigida para uma aprendizagem contínua relativa às suas próprias especialidades e padrões de prática, no lugar de uma complacência com obrigações enfraquecedoras de mudanças sem fim exigidas por outros (muitas vezes sob a aparência de aprendizagem contínua ou aperfeiçoamento); criação e reconhecimento das tarefas de alta complexidade, com níveis de status e remuneração apropriados para tal complexidade.

Tentando distanciar-se das definições clássicas de profissionalismo e autonomia, Hargreaves busca uma alternativa àquela autonomia autoprotetora, que circunscreve todo o poder de decisão e de competência ao profissional. Definitivamente essa visão de autonomia não existe mais para o trabalho docente, muito embora possa se discutir que o mito de que uma autonomia político-pedagógica seria típico do profissionalismo docente, ou que possa haver uma autonomia relativa pelo menos quanto a decisões técnicas de sala de aula. Obviamente, a busca de um modelo de autonomia baseado no profissionalismo clássico não é só inadequado, mas insuficiente para os desafios educativos que se colocam para o magistério. Contudo, a heteronomia pode não ser uma alternativa satisfatória. Pensamos que formas coletivas de exercer o trabalho pedagógico, que considerem os saberes docentes teóricos e práticos e que, ao mesmo tempo, considerem a comunidade esco- 
lar como parte integrante de todo o processo educativo, podem ser construídas. Como indica Hypolito:

Profissionalismo tem que significar a melhoria do trabalho profissional, mas também a melhoria da qualidade social do ensino. Assim, as comunidades, grupos e movimentos sociais têm que ser auscultados quanto à qualidade social da educação não sendo reduzidos a "clientes", como quer o neoliberalismo, mas como agentes que possuem identidades de raça, sexo e classe que, muitas vezes, podem colidir com as identidades construídas pelos docentes. Dessa maneira, a profissionalização tem que incluir o senso político de lidar com a idéia de que as definições de curriculum, conteúdos e métodos, devem resultar menos da sabedoria iluminada do profissional e mais das inter-relações com as realidades culturais nas quais se circunscreve o ato educativo. (Hypolito, 1999, p. 98-99)

Os modelos de profissionalismo, embora possam contribuir para uma melhor compreensão das implicações das reformas sobre o cotidiano escolar e a identidade profissional dos docentes, não podem ser tomados de forma pura e excludente, pois não há modelos fixos. São categorias analíticas que visam mostrar possibilidades e implicações de modelos que convivem em contradição. Algumas das características apontadas anteriormente podem ser encontradas nas políticas de formação e avaliação docente propostas no Brasil desde meados da década de 1990.

\section{Investigando a identidade docente: algumas consideraçōes}

A identidade profissional dos docentes é assim entendida como uma construção social marcada por múltiplos fatores que interagem entre si, resultando numa série de representações que os docentes fazem de si mesmos e de suas funções, estabelecendo, consciente e inconscientemente, negociações das quais certamente fazem parte suas histórias de vida, suas condições concretas de trabalho, o imaginário recorrente acerca dessa profissão - certamente marcado pela gênese e desenvolvimento histórico da função docente -, e os discursos que circulam no mundo social e cultural acerca dos docentes e da escola.

As possibilidades de investigação das identidades docentes são múltiplas, dada a imensa variedade das condições de formação e atuação profissional desses sujeitos, a diversidade de artefatos culturais e discursivos envolvidos na produção dessas identidades e a complexidade dos fatores que interagem nos processos de identificação dos docentes com o seu trabalho. As pesquisas, portanto, serão sempre parciais (aliás como com qualquer outro objeto ou tema de estudo), provisórias e restritas a alguns aspectos ou fatores implicados nos processos de identificação dos professores. Perder a ilusão de um conhecimento definitivo e de totalidade acerca dessa questão é uma precaução epistemológica importante se considerarmos a heterogeneidade da categoria docente e a própria instabilidade das identidades no mundo contemporâneo.

Em um tempo recente, as investigações que problematizavam a identidade e a profissionalização docente parecem ter buscado aspectos unificadores e fundantes da identidade profissional dessa categoria: a classe social, a natureza do processo de trabalho, o gênero, a história de vida, a formação profissional, etc. Talvez um caminho produtivo para a pesquisa seja buscar as diferenças, as descontinuidades, as divisões dessa categoria, privilegiando as narrativas dos professores e das professoras acerca de si mesmos e de seus contextos de trabalho. Não para reificar seus próprios pontos de vista ou tomá-los como a medida mais justa do que de fato acontece, mas talvez para nos aproximarmos da dinâmica contraditória e fragmentada em que estão mergulhados. 
Professores e professoras são sujeitos divididos entre éticas e demandas distintas, e, muitas vezes, contraditórias: burocráticas, morais, pessoais, profissionais, técnicas, etc. Sair do conforto de buscar enquadrar a identidade profissional docente em alguns tipos ideais ou explicá-la a partir de algum elemento fundacional talvez seja o maior desafio que podemos enfrentar relativamente a essas questões. Isso não significa desconsiderar as descrições expostas anteriormente de processos de trabalho que ajudam a caracterizar diferentes concepções sobre profissionalismo docente. Contudo, é importante resguardar que essas descrições não podem ser concebidas como modelos puros, mas como práticas discursivas, mais ou menos reforçadas pelos discursos oficiais e outros discursos que interpelam os professores e as professoras na produção de suas identidades.

\section{Referências bibliográficas}

ANADON, S.; GARCIA, M. M. A. Trabalho e identidade docente nos discursos educacionais oficiais da Revista "Nova Escola". In: SEMINÁRIO DE PESQUISA EM EDUCAÇÃO DA REGIÃO SUL - ANPED-SUL, 5., Mesa-Redonda... Curitiba: PUC-PR, 2004.

APPLE, M. W. Relações de classe e de gênero e modificações no processo de trabalho docente. Cadernos de Pesquisa, São Paulo, n. 60, p. 3-14, fev. 1987.

. Ensino e trabalho feminino: uma análise comparativa da história e ideologia. Cadernos de Pesquisa, São Paulo, n. 64, p. 14-23, fev. 1988.

ARROYO, M. Mestre, professor, trabalhador. Belo Horizonte: FE-UFMG, 1985.

BALL, S. Education reform: a critical and post-structural approach. Buckingam: Open University Press, 1994.

CODO, W. (org.) Educação: carinho e trabalho. UnB/CNTE, Petrópolis: Vozes, 1998.

HARGREAVES, A.; GOODSON, I. Teachers' professional lives: aspirations and actualities. In: lives. London/Washington DC: Falmer Press, p.1-27, 1996.

Teachers' professional

HYPOLITO, A. M. Processo de trabalho na escola: uma análise a partir das relações de classe e de gênero. 1994. Dissertação (Mestrado) - Universidade Federal de Minas Gerais, Belo Horizonte. 1994.

. Relações de gênero e de classe social na análise do trabalho docente. Cadernos de Educação, Pelotas, n. 4, p. 5-18, 1995.

. Trabalho docente, classe social e relações de gênero. Campinas: Papirus, 1997.

. Trabalho docente e profissionalização: sonho prometido ou sonho negado? Desmistificando a profissionalização do magistério. Campinas: Papirus, p. 81-100, 1999.

HYPOLITO, A. M.; VIEIRA, J. S. Reestruturação educativa e trabalho docente: autonomia, contestação e controle. In: Hypolito, A. M.; Vieira, J. S.; Garcia, M. M. A. Trabalho docente: formação e identidades. Pelotas: Seiva Publicações, 2002. p.271-283.

HYPOLITO, A. M. et al. Trabalho docente, profissionalização e identidade: contribuições para a constituição de um campo de estudo. Educação em Revista, Belo Horizonte, n.37, p.123-138, jul.2003.

LAWN, M. Os professores e a fabricação de identidades. Currículo Sem Fronteiras, v. 1, n. 2, jul./dez. 2001. Disponível em: http:/ /www.curriculosemfronteiras.org/vol1iss2articles/lawn.htm.

ROBERTSON, S. Teachers' work, restructuring and postfordism: constructing the new 'professionalism'. In: HARGREAVES, A.; GOODSON, I. Teachers' professional lives. London/Washington DC: Falmer Press, 1996.

. Política de re-territorialização: espaço, escola e docentes como classe profissional. Currículo Sem Fronteiras. v. 2, n. 2, jul./dez. 2002. Disponivel em: http://www.curriculosemfronteiras.org/vol2iss2articles/Robertson.htm 
VIEIRA, J. S. Limites da racionalização do processo de trabalho docente. 1992. Dissertação (Mestrado) - Faculdade de Educação, Universidade Federal do Rio Grande do Sul, Porto Alegre. 1992.

Um negócio chamado educação: qualidade total, trabalho docente e identidade. Pelotas: Seiva Publicações, 2004.

Recebido em 27.07.04

Aprovado em 03.03 .05

Maria Manuela Alves Garcia é doutora em Educação pela Universidade Federal do Rio Grande do Sul, atualmente é professora da Faculdade de Educação na Universidade Federal de Pelotas e, também, atual coordenadora do Programa de Pós-Graduação em Educação na mesma universidade.

Álvaro Moreira Hypolito é doutor em Currículo e Ensino pela Universidade de Wisconsin, Madison (EUA). Atualmente é professor da Faculdade de Educação na Universidade Federal de Pelotas, e um dos editores da revista Currículo sem Fronteiras <www.curriculosemfronteiras.org $>$.

Jarbas Santos Vieira é doutor em Educação pela Universidade Federal do Rio Grande do Sul e professor da Faculdade de Educação na Universidade Federal de Pelotas. 